\title{
Malignant melanoma types and treatment
}

\author{
Malign melanom tipleri ve tedavisi

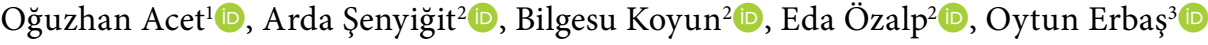 \\ ${ }^{1}$ Trakya University Medical Faculty, Edirne, Turkey \\ ${ }^{2}$ Dokuz Eylül University Faculty of Medicine, Izmir, Turkey \\ ${ }^{3}$ Department of Physiology, Istanbul Bilim University, Faculty of Medicine, Istanbul, Turkey
}

\section{ABSTRACT}

Malignant melanoma is the skin cancer with the highest mortality rate and increasing prevalence. Melanoma has clinical and pathological subtypes. Criteria have been defined for early and histopathological diagnosis of malignant melanoma. Many treatments according to stage and clinical characteristics have been developed. Particularly, Today, thanks to immunotherapy of late-stage cancer, progression of the disease has halted and survival time has significantly increased.

Keywords: Malignant melanoma, melanoma treatment, stages of melanoma, types of malignant melanoma.

\section{öz}

Malign melanoma, ölüm oranı yüksek ve sıklığı artan bir deri kanseridir. Melanomun klinik ve patolojik alt tipleri vardır. Malign melanoma tanısı için erken ve histopatolojik tanı kriterleri tanımlanmıştır. Evre ve klinik özelliklere göre pek çok tedavi geliştirilmiştir. Özellikle günümüzde ileri evre kanserde geç evre kanser immünoterapi sayesinde hastalığın progresyonu engellenmiş ve sağkalım süresi anlamlı̈lçüde artmıştır.

Anahtar sözcükler: Malign melanom, melanoma tedavisi, malign melanom tipleri, melanom evreleri.

Melanoma is a neoplasia that originates from neural crest melanocytes and nevus cells believed to develop as a result of melanocyte differentiation. It is a malignant tumor that occurs in regions containing melanocytes (skin, mucosa, eyes, and central nervous system). ${ }^{[1]}$

\section{Epidemiology}

Incidence of melanoma among all cancers is $4 \%$ in females and $5 \%$ in males. ${ }^{[2]}$ Despite its low probability of transformation, it may show characteristics of rapid growth and systemic spread. ${ }^{[3]}$ While malignant melanoma accounts for $4 \%$ of all skin cancers, malignant melanoma causes $80-85 \%$ of all skin-cancer related deaths. Approximately 160,000 new cases of malignant melanoma and 48,000 deaths malignant melanoma-related deaths occur per year worldwide. ${ }^{[4]}$

\section{Etiopathogenesis}

As with other types of cancer, melanomas are caused by mutations that provide additional function to various protooncogenes, or result in loss of function of tumor suppressor genes. Activation of oncogenes such as NRAS, BRAF, and KIT, as well as inactivation of tumor suppressor genes including cyclin-dependent kinase inhibitor 2A (CDKN2A), PTEN, and p53 and epigenetic changes (hypermethylation of tumor suppressor

Received: May 30, 2019 Accepted: June 26, 2019 Published online: October 31, 2019

Correspondence: Eda Özalp. Dokuz Eylül Üniversitesi Tıp Fakültesi, 35340 Balçova, İzmir, Türkiye. Tel: +90 554 - 9056365 e-mail: eda.ozalp99@gmail.com 
genes or hypomethylation of oncogenes) may be effective in melanomagenesis. ${ }^{[3]}$

Classification of malignant melanoma as familial and non-familial finds approximately 10\% of cases are familial. ${ }^{[3]}$ Mutations of the CDKN2A gene at locus 9p21 have been demonstrated in approximately one-third of families with malignant melanoma. The CDKN2A gene synthesizes p16INK4A and p14ARF proteins and plays a role as a tumor suppressor gene in the regulation of the cell cycle. The CDKN2A gene products p16 and p14 have regulatory effects on the cell cycle through the retinoblastoma $(\mathrm{Rb})$ protein and p53

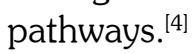

Another important pathway in the development of malignant melanoma is the NRAS/MAPK (mitogen-activated protein kinase) pathway. Most RAS and BRAF mutations identified in sporadic malignant melanomas cause continuous activation of this pathway. NRAS is a protooncogene of the RAS family. RAF plays a role as a RAS inhibitor and is a critical checkpoint in the RAS and MAPK pathways. RAF has three isoforms. Mutations of the BRAF isoform occurs in $50-60 \%$ of sporadic malignant melanomas. In recent years, treatments that target the BRAF pathway (vemurafenib, dabrafenib) have risen to prominence. Another pathway is the PI3K/AKT (phosphoinositide-3kinase-protein kinase $\mathrm{B}$ ) pathway. The PTEN tumor suppressor gene plays an important regulatory function in this pathway (Figure 1).

Sun exposure is the most important environmental factor in the etiology of malignant melanoma. ${ }^{[4]}$ Other risk factors include: skin type (fair skin), environmental factors (ultraviolet exposure), genetic basis (CDKN2A gene mutation), large number of previous melanocytic nevi, dysplastic nevus, and previous history of melanoma. ${ }^{[5]}$

\section{Types and clinical characteristics}

Incidence of mucosal melanoma, which originates from melanocytes located in mucosa lining the respiratory, gastrointestinal, and urogenital regions, is only about $1.4 \%$ among all melanomas. ${ }^{[6]}$ Mucosal melanomas have relatively higher mortality rates compared to cutaneous melanomas. While five-year survival of cutaneous melanoma is $80 \%$, this is only $25 \%$ in mucosal melanomas. ${ }^{[7]}$ Since mucosal melanomas occur in regions without exposure to sunlight, its risk factors are not completely defined. Smoking is a proposed risk factor for oral mucosal melanoma and oral pigmented lesions have been found more common among smokers. ${ }^{[6]}$

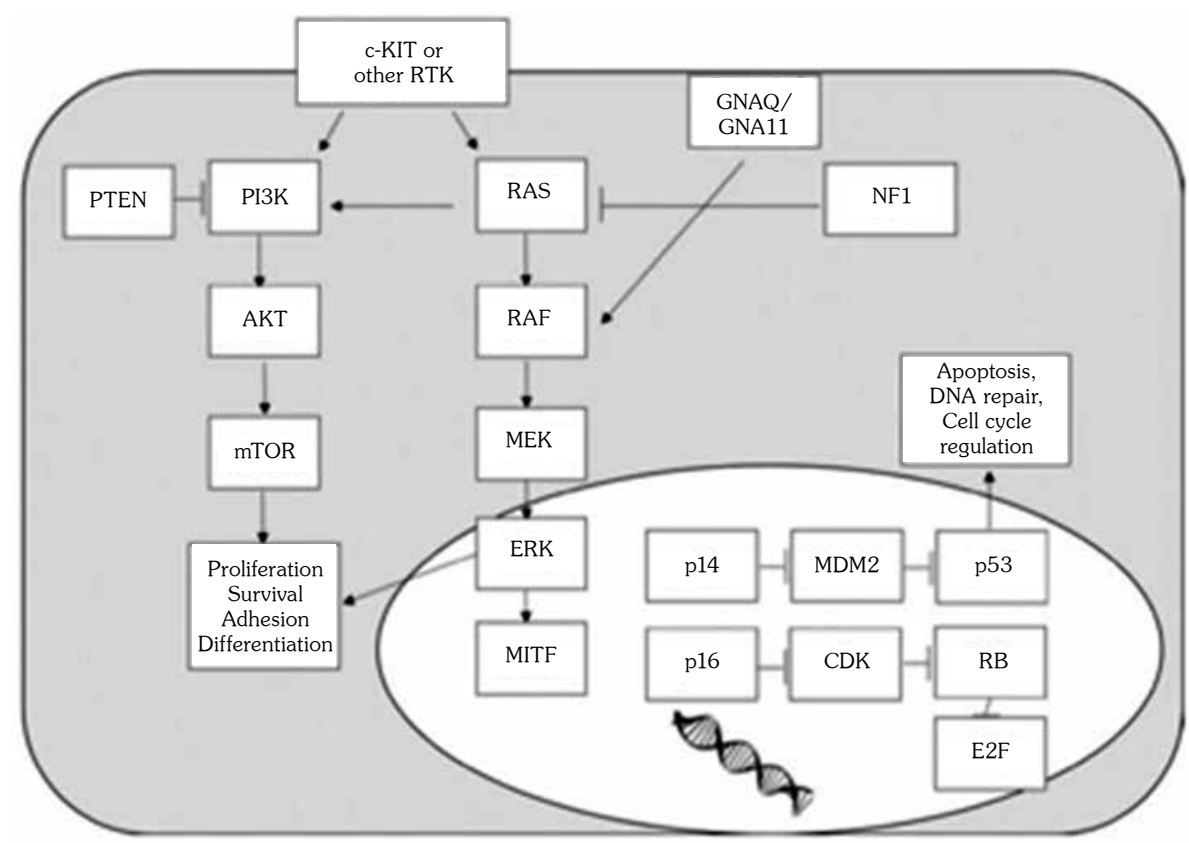

Figure 1. Signal transmitting pathways of varying activity which contribute to malignant melanoma formation and progression. ${ }^{[3]}$ 
In dermoscopic examination of malignant melanoma, three main characteristics are important in benign-malignant differentiation including asymmetry, atypical pigment network, and blue-white foci. ${ }^{[8]}$

The four subtypes of cutaneous melanoma based on clinical and pathologic features are: superficial spreading melanoma, nodular melanoma, lentigo melanoma, and acral lentiginous melanoma (ALM). Although four types of melanoma were initially defined according to localization, classification based on main clinical features as monophasic and biphasic has been more convenient. The first phase, known as the tumor's radial growth phase (in situ period) is followed by the vertical growth phase (invasive period) in which neoplastic cells cross the dermoepidermal junction and spread to the papillary dermis..$^{[5]}$ Nodular melanoma is accepted as having no radial growth phase and only vertical growth phase. ${ }^{[1]}$

Superficial spreading malignant melanoma subtype is most common in fair-skinned individuals and accounts for $70 \%$ of all malignant melanomas. Regions of the body with the most intermittent sun exposure are the chest in men and legs in women. The lesion initially begins as a macule or patch with asymmetry, color variance, and irregular border, and later develops into a papule or nodule. ${ }^{[4]}$ This type of melanoma has the greatest risk of development from previous melanocytic nevi. ${ }^{[1]}$

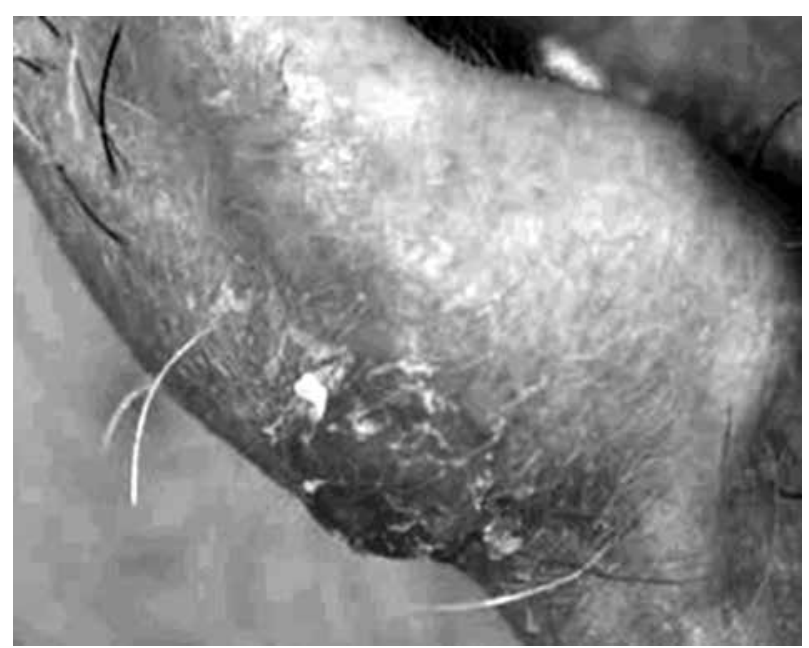

Figure 2. Nodular melanoma-nonpigmented erythematous nodule. ${ }^{[10]}$
Nodular malignant melanoma is the second most common malignant melanoma subtype in fair-skinned individuals and accounts for 15-30\% of all malignant melanomas. ${ }^{[4]}$ It is most commonly found in the head and neck regions and generally manifests as a rapidly expanding swelling. Onethird of nodular melanomas are amelanotic, or non-pigmented (Figure 2). ${ }^{[9]}$

Lentigo malignant melanoma comprise less than $15 \%$ of all cutaneous malignant melanomas and is mostly seen in the elderly. It is more common in women than men. The melanoma shows local expansion and slow progression, being the least aggressive melanoma. ${ }^{[10]}$ It manifests as a brownblack colored patch with color variance and asymmetry. ${ }^{[10]}$ This melanoma type has the best prognosis. Cumulative effect of ultraviolet (UV) radiation plays an important role in its etiology. It has significantly long in situ stage (radial growth phase) of 5-20 years (Figure 3). ${ }^{[1]}$

Acral lentiginous malignant melanoma composes $5-10 \%$ of cutaneous malignant melanomas and is unrelated to UV exposure. ${ }^{[4]}$ It typically shows color variation, irregular borders, asymmetry, and manifests as a macule ranging from brown to black color. This melanoma type is localized on the palmoplantar and subungual region. Brown or black band appearance on the nail, nail dystrophia, and Hutchinson sign are common clinical findings ${ }^{[8]}$ In the vertical growth phase, the tumor swells forming ulcerated nodules prone to bleeding. When located on the nail, it

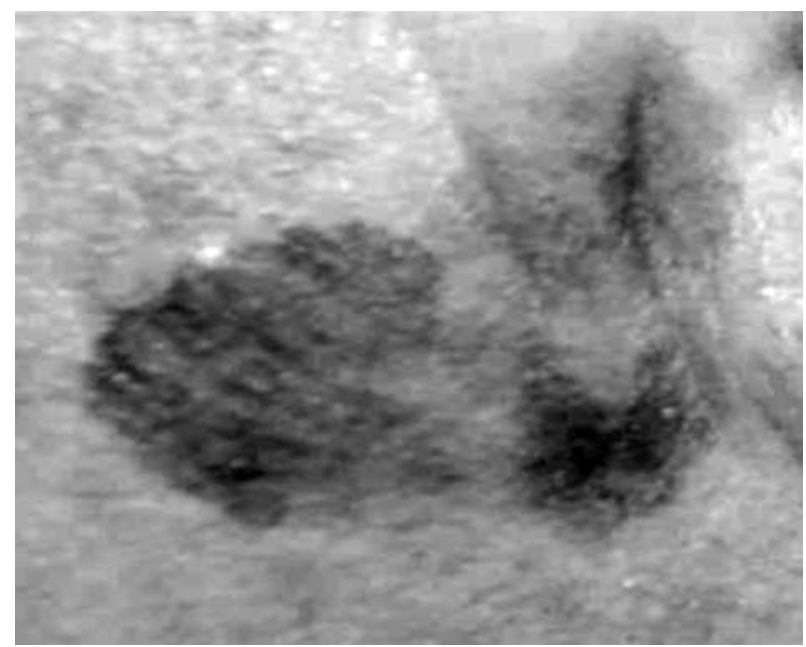

Figure 3. Lentigo malignant melanoma-irregular borders, patch appearance with color variance. ${ }^{[10]}$ 


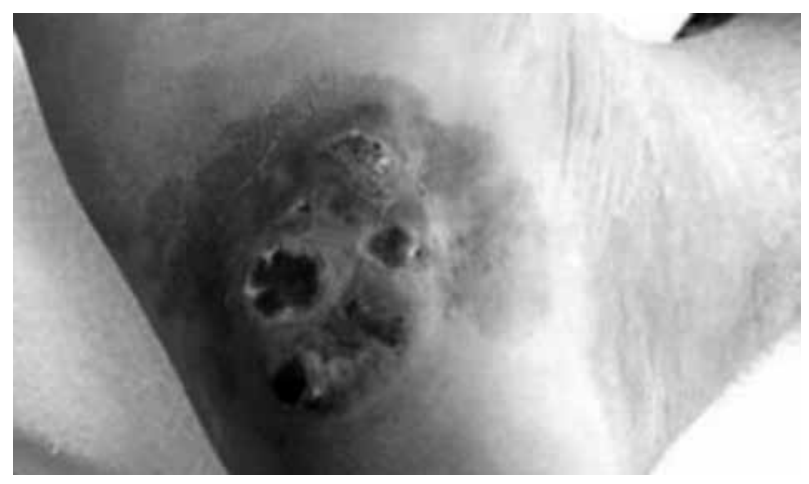

Figure 4. Acral gelatinous malignant melanoma-ulceration on macular base, nodular lesion. ${ }^{[7]}$

usually occurs on the thumb or large toe of the hands and feet (Figure 4). ${ }^{[1]}$

Desmoplastic melanoma is a rare malignant melanoma subtype. ${ }^{[1]}$ This rare variant is characterized by spindle cells surrounded by fibrocollagenous stroma, with histologically abundant desmoplasia. Often asymptomatic, it clinically manifests as an amelanotic nodule..$^{[1]}$

\section{PATHOLOGIC STAGING}

The most current staging system is the tumornode-metastasis (TNM) system, renewed by the American Joint Committee on Cancer (AJCC) in 2010 and is based on primary tumor (T), regional lymph node presence $(\mathrm{N})$, and distant metastasis (M). ${ }^{[12]}$ Use of primary tumor thickness as a diagnostic criterion was first proposed by Alexander Breslow in the 1970s. ${ }^{[13]}$ Using the TNM classification, patients can be staged from in situ melanoma (Stage 0) to metastatic melanoma (Stage 4). This staging method is useful in determining the best treatment options, prognosis, and survival rates. ${ }^{[14]}$

\section{Stages:}

In situ melanoma (Stage 0): Abnormal melanocytes are observed in the epidermis, which may later develop into cancer and spread to healthy neighboring tissue. ${ }^{[15]}$

Localized melanoma (Stage I, II): Patients diagnosed with localized melanoma have a greater advantage than other patients ${ }^{[13]}$ and $82 \%$ of diagnosed melanoma patients fall into this stage. ${ }^{[16]}$

Stage I: Includes low-risk primary melanoma patients without regional or distant metastasis
(T1a-T2a). The stage is separated into Stage IA or IB depending on primary tumor, mitosis rate, and ulceration.

Stage IA: Tumor thickness $<1 \mathrm{~mm}$ regardless of ulceration

Stage IB: Tumor thickness between 1-2 mm without ulceration

Stage II: Includes primary tumor at high risk of recurrence, without lymphatic involvement or distant metastasis (T2b-T4b). Stage II is divided into Stage IIA, IIB, or IIC depending on tumor thickness and ulceration. ${ }^{[1]}$

Stage IIA: Ulceration and tumor thickness of 1-2 $\mathrm{mm}$; or no ulceration and tumor thickness of 2-4 $\mathrm{mm}$.

Stage IIB: Ulceration and tumor thickness of 2-4 $\mathrm{mm}$; or no ulceration and tumor thickness $>4 \mathrm{~mm}$.

Stage IIC: Tumor thickness $>4 \mathrm{~mm}$ and ulceration. ${ }^{[15]}$

Regional metastatic melanoma (Stage III): Patients with regional metastasis (regional lymph nodes, satellite and/or in-transit metastases, etc.) show heterogenous distribution according to staging and prognosis. ${ }^{[3]}$ Stage III patients are staged as Stage IIIA, IIIB, IIIC, and IIID according to lymphatic spread ${ }^{[15]}$ and $9 \%$ of diagnosed melanoma patients fall into this stage. ${ }^{[16]}$

Stage IIIA: Tumor has ulceration and tumor thickness is $<1 \mathrm{~mm}$; or no ulceration and thickness $<2 \mathrm{~mm}$. Sentinel lymph node biopsy shows cancer in 1-3 lymph nodes.

\section{Stage IIIB:}

- Origin of cancer or primary tumor cannot be identified, and one of the following criteria:

- Cancer in one lymph node in physical examination or imaging

- Microsatellite tumors on or below the skin, satellite tumors and/or in-transit metastasis

Or

- Tumor has ulceration and thickness is $<1 \mathrm{~mm}$ or no ulceration and thickness $<2 \mathrm{~mm}$, and one of the following criteria: 
- Cancer in 1-3 lymph nodes in physical examination or imaging

- Microsatellite tumors on or below the skin, satellite tumors and/or in-transit metastasis

- Tumor has ulceration and thickness of 1-2 $\mathrm{mm}$ or no ulceration and thickness of

2-4 $\mathrm{mm}$ and one of the following criteria:

- Cancer detected in 1-3 lymph nodes

- Microsatellite tumors on or below the skin, satellite tumors and/or in-transit metastasis

\section{Stage IIIC:}

- Origin of cancer or primary tumor cannot be identified, and one of the following criteria:

- Cancer in 2-3 lymph nodes

- Cancer in one lymph node and microsatellite tumors on or below the skin, satellite tumors and/or in-transit metastasis

- Cancer in four or more lymph nodes or in any number of lymph nodes that are matted together

- Cancer in two or more lymph nodes and/or in any number of lymph nodes that are matted together. There are microsatellite tumors, satellite tumors, and/or in-transit metastases on or under the skin

\section{$\mathrm{Or}$}

- The tumor has thickness $<2 \mathrm{~mm}$ with or without ulceration, or is $<4 \mathrm{~mm}$ without ulceration, and one of the following criteria:

- Cancer in one lymph node and microsatellite tumors on or below the skin, satellite tumors and/or in-transit metastasis

- Cancer in four or more lymph nodes or in any number of lymph nodes that are matted together

- Cancer in two or more lymph nodes and/or in any number of lymph nodes that are matted together. There are microsatellite tumors, satellite tumors, and/or in-transit metastases on or under the skin

\section{Or}

- Tumor has ulceration and thickness $<2 \mathrm{~mm}$, or no ulceration and $<4 \mathrm{~mm}$ thickness. Cancer is observed in one or more lymph nodes or in any number of lymph nodes that are matted together. There are microsatellite tumors, satellite tumors, and/or in-transit metastases on or under the skin.

$\mathrm{Or}$

- Tumor has ulceration and thickness $>4 \mathrm{~mm}$. Cancer is observed in one or more lymph nodes. There are microsatellite tumors, satellite tumors, and/or in-transit metastases on or under the skin.

Stage IIID: Tumor is thicker than $4 \mathrm{~mm}$ and has one of the following criteria:

- Cancer in four or more lymph nodes or in any number of lymph nodes that are matted together

- Cancer in two or more lymph nodes and/or in any number of lymph nodes that are matted together. There are microsatellite tumors, satellite tumors, and/or in-transit metastases on or under the skin

Distant metastatic melanoma (Stage IV): In this stage, cancer has spread to tissues and organs in the lungs, liver, brain, spinal cord, bone, soft tissue (including muscle), and gastrointestinal system and/or regional/distant lymph nodes. Cancer may spread to more distant regions than its origin on the skin. ${ }^{[15]}$ About $4 \%$ of patients fall into this stage. ${ }^{[16]}$ There are no subtypes (Table 1). ${ }^{[17]}$

\section{DIAGNOSIS}

During clinical examination, pigmented lesions with characteristics of the "ABCDE" rules are suspected as melanoma (Figure 5). The ABCDE system benefits both doctors and patients in early detection of melanoma. The ABCDE rules are: Asymmetry, irregular Border, Color variance, Diameter of $>6 \mathrm{~mm}$, and Evolution/Elevation of the lesion over time. Detection of such lesions require evaluation of adjacent tissue for satellite lesions or in-transit metastatic foci. After the relevant lesion is comprehensively assessed, the remaining cutaneous surfaces (scalp, perineum region, interdigital space, genital, and subungual regions) should be closely examined for presence 
Table 1. Tumor-node-metastasis classification of melanoma ${ }^{[17]}$

\begin{tabular}{|c|c|c|}
\hline Classification & Thickness (mm) & Ulceration presence/mitosis \\
\hline \multicolumn{3}{|l|}{$\mathrm{T}$} \\
\hline T-in situ & NA & NA \\
\hline \multirow[t]{2}{*}{$\mathrm{T} 1$} & $\leq 1.00$ & a: Ulceration and no mitosis $<1 / \mathrm{mm}^{2}$ \\
\hline & & b: Ulceration or mitosis $\geq 1 / \mathrm{mm}^{2}$ \\
\hline \multirow[t]{2}{*}{$\mathrm{T} 2$} & $1.01-2.00$ & a: No ulceration \\
\hline & & b: Ulceration \\
\hline \multirow[t]{2}{*}{ T3 } & $2.01-4.00$ & a: No ulceration \\
\hline & & b: Ulceration \\
\hline \multirow[t]{2}{*}{$\mathrm{T} 4$} & $>4.00$ & a: No ulceration \\
\hline & & b: Ulceration \\
\hline $\mathrm{N}$ & Metastatic lymph nodes & Nodal metastatic burden \\
\hline No & 0 & NA \\
\hline \multirow[t]{2}{*}{ N1 } & 1 & a: Micrometastasis* \\
\hline & & b: Macrometastasis $\dagger$ \\
\hline \multirow[t]{3}{*}{ N2 } & $2-3$ & a: Micrometastasis* \\
\hline & & b: Macrometastasis $\dagger$ \\
\hline & & $\begin{array}{l}\text { c: In-transit metastasis/satellites } \\
\text { without metastatic nodes }\end{array}$ \\
\hline N3 & $\begin{array}{l}4+\text { metastatic nodes or matted nodes } \\
\text { or in-transit metastasis/satellites with } \\
\text { metastatic nodes }\end{array}$ & \\
\hline
\end{tabular}

NA: Not applicable; " Micrometastases are diagnosed after sentinel lymph node biopsy; $†$ Macrometastases are defined as clinically detectable nodal metastases confirmed pathologically.

of other suspicious lesions. All lesions with benign appearance should be recorded and all lymph node regions should be palpated for lymphadenopathy. ${ }^{[18]}$

The ABCDE criteria have been confirmed according to sensitivity, specificity, and accurate diagnosis in many studies (Figure 5). ${ }^{[19]}$

Another screening method, the "Glasgow Seven-Point Checklist", includes three major (change in size of lesion, irregular pigmentation, and irregular borders) and four minor criteria (diameter $>7 \mathrm{~mm}$, inflammation of lesion, crusting, and itch or altered sensation). ${ }^{[19]}$

\section{TREATMENT}

Melanoma has many treatment options. Some treatments are standard while others are under clinical experimentation. Nowadays, surgery, chemotherapy, immunotherapy, and radiotherapy modalities are used. Selection of treatment modality varies according to type and stage of melanoma. ${ }^{[15]}$

\section{Surgery}

Surgical management of melanoma is planned according to diagnostic biopsy, wide local excision, and lymph node staging. Pathologic
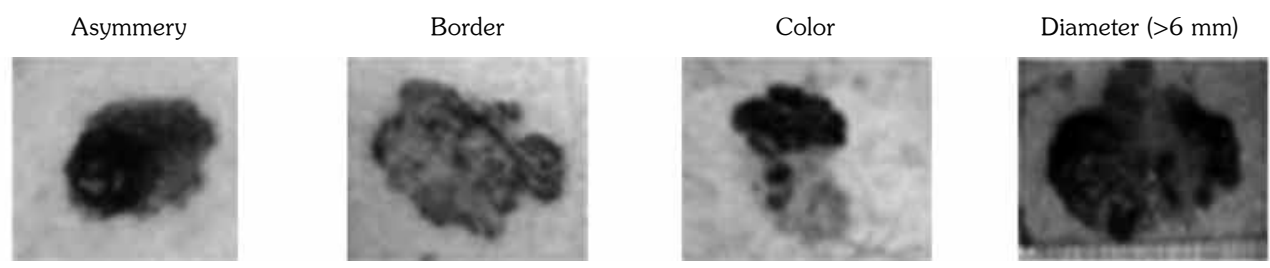

Evolution or elevation

Figure 5. ABCDE system for melanoma diagnosing. ${ }^{[18]}$ 
features of the primary tumor, anatomical localization, patient preference, comorbidities, and functional and cosmetic results should be considered in patients undergoing surgery. ${ }^{[20]}$ Surgical resection of the tumor is the primary treatment of melanoma in all stages. Local excision is used to remove the melanoma and a portion of normal surrounding tissue. ${ }^{[15]}$ Primary goal of surgical treatment is removal of the primary lesion with clean surgical margins, accurate evaluation of the tumor's regional spread, and ensuring disease-free survival with treatment. ${ }^{[21]}$ Malignant melanoma most commonly metastasizes to regional lymph nodes, and sentinel lymph node involvement is the most important factor affecting prognosis. Sentinel lymph node biopsy is used to determine metastatic disease. ${ }^{[22]}$

Many recent studies have investigated the benefit of metastasectomy on survival. Important advancements in the treatment of metastatic disease have emerged and surgical treatment has an important place in the management of this patient group. ${ }^{[23]}$

After resection of melanomas with surgery, some patients undergo chemotherapy to kill remaining cancer cells. Since chemotherapy reduces risk of recurrence after surgery, this is considered adjuvant treatment. ${ }^{[15]}$

\section{Radiotherapy}

Radiotherapy uses high-energy X-rays and other types of radiation to kill cells or prevent growth. Administration of radiation therapy (internal/external) is based on cancer type and stage. Radiotherapy can also be used to alleviate symptoms and provide palliative care. ${ }^{[15]}$

Radiotherapy is an important treatment modality in recurrent or metastatic melanoma patients who require local control.[24] One randomized controlled study on 250 patients applied 48 Gy adjuvant radiotherapy for treatment purposes. ${ }^{[25]}$ Use of adjuvant radiotherapy after complementary surgical resection was found to significantly reduce melanoma recurrence in the adjuvant radiotherapy group compared to the control group who did not receive radiotherapy; however, it did not lead to significant difference in recurrence-free survival and general survival rates. ${ }^{[25,26]}$
Various studies have experimented with use CTLA-4 and PD-1 antagonist drugs in combination with radiotherapy. One study reported combined use of radiotherapy and ipilimumab increased survival in patients with brain metastasis. Another study suggested radiotherapy and anti-PD-1 combined treatment was effective in treatment of patients with mucosal melanoma; however, this combination treatment requires further research. ${ }^{[27]}$

\section{Immunotherapy}

Elimination of tumor cells occurs through a sensitive balance between stimulant pathways and suppressor checkpoints of the immune system. The purpose of immunotherapy is to fundamentally target these checkpoints, inhibit tumor tolerance, and as a result, eliminate tumor cells. ${ }^{[28]}$

In recent years, our understanding of the role of the immune system in the control of tumor proliferation has led to the success of therapies targeted to act upon immune pathways, especially in melanoma. Cancer cells nullify immune mechanisms with escape mechanisms. Under normal circumstances, immune checkpoints developed to protect the person from autoimmunity and suppress prolonged inflammatory response play a negative controller role on $\mathrm{T}$ cells. The most well-known inhibitor receptors are cytotoxic T-lymphocyte-associated antigen 4 (CTLA-4) and programmed cell death receptor 1 (PD-1). ${ }^{[28,29]}$

\section{CTLA4}

$\mathrm{T}$ lymphocytes detect antigens presented by antigen presenting cells (APC) or major histocompatibility complex (MHC) on the surface of tumor cells and are activated. In order for complete activation of $\mathrm{T}$ cell response, the CD28 molecule on the $\mathrm{T}$ cell must bind to the B7 molecule on APCs or the target cell. CTLA-4 is transported to the active $\mathrm{T}$ cell surface and competes with $\mathrm{CD} 28$ for the B7 binding region. If CTLA-4 binds to the $\mathrm{B} 7$ region, it forms an inhibitory signal that controls immune response. If CTLA- 4 binds to an antibody, preventing binding to $\mathrm{B} 7$, this eliminates the inhibitory effect, thus activating the immune system and removing the brake mechanism on the immune system (Figure 6). ${ }^{[28,29]}$ Similarly, in 
the microenvironment of the tumor, the $\mathrm{T}$ cell detects the antigen presented by $\mathrm{MHC}$ on the tumor cell.

\section{PD1}

As mentioned before, the immune system contains various checkpoints and inhibitory pathways to prevent eradication of normal host cells (autoimmunity). One example is the interaction between programmed death-1 (PD-1) and programmed death ligand-1 (PD-L1). Programmed death- 1 is found on the surfaces of $\mathrm{T}$ cells, B cells, and natural killer (NK) cells, and can also be expressed on the surface of cancer cells. In the microenvironment of the tumor, the $\mathrm{T}$ cell detects the antigen presented by MHC on the tumor cell surface. However, the tumor cell increases expression of a protein called PD-L1, allowing it to bind to another inhibitory molecule known as PD-1 on the T cell. With this binding, immune response (brake mechanism) is suppressed. Therefore, if PD-L1 or PD-1 can be blocked by an antibody, immune response is allowed to form in the microenvironment of the tumor. Discovery of this pathway has developed inhibitors of checkpoints. Nivolumab and pembrolizumab are anti-PD-1 antibodies (Figure 7). ${ }^{[28,29]}$

\section{Ipilimumab}

Ipilimumab, a human monoclonal antibody that blocks CTLA-4 and has immunoglobulin G1 (Ig-G1) structure, was approved for use by the Food and Drug Administration (FDA) for melanoma treatment in 2011. When the interaction between CTLA4 and B7 receptor expressed on the surface of antigen presenting cells is blocked, inhibition on T cells is removed, allowing immune response to malignant cells. ${ }^{[30]}$

\section{Nivolumab}

Nivolumab is a human IgG4 monoclonal antibody that inhibits activity by binding to PD-1 and blocking PD-L1 and PD-L2 interaction. ${ }^{[31]}$

When the inhibitory pathway is blocked, antitumor response is achieved with T-cell activation. Nivolumab has shown success in various clinical studies on late-stage melanoma patients. Treatment in combination with ipilimumab has also been tested. ${ }^{[29]}$

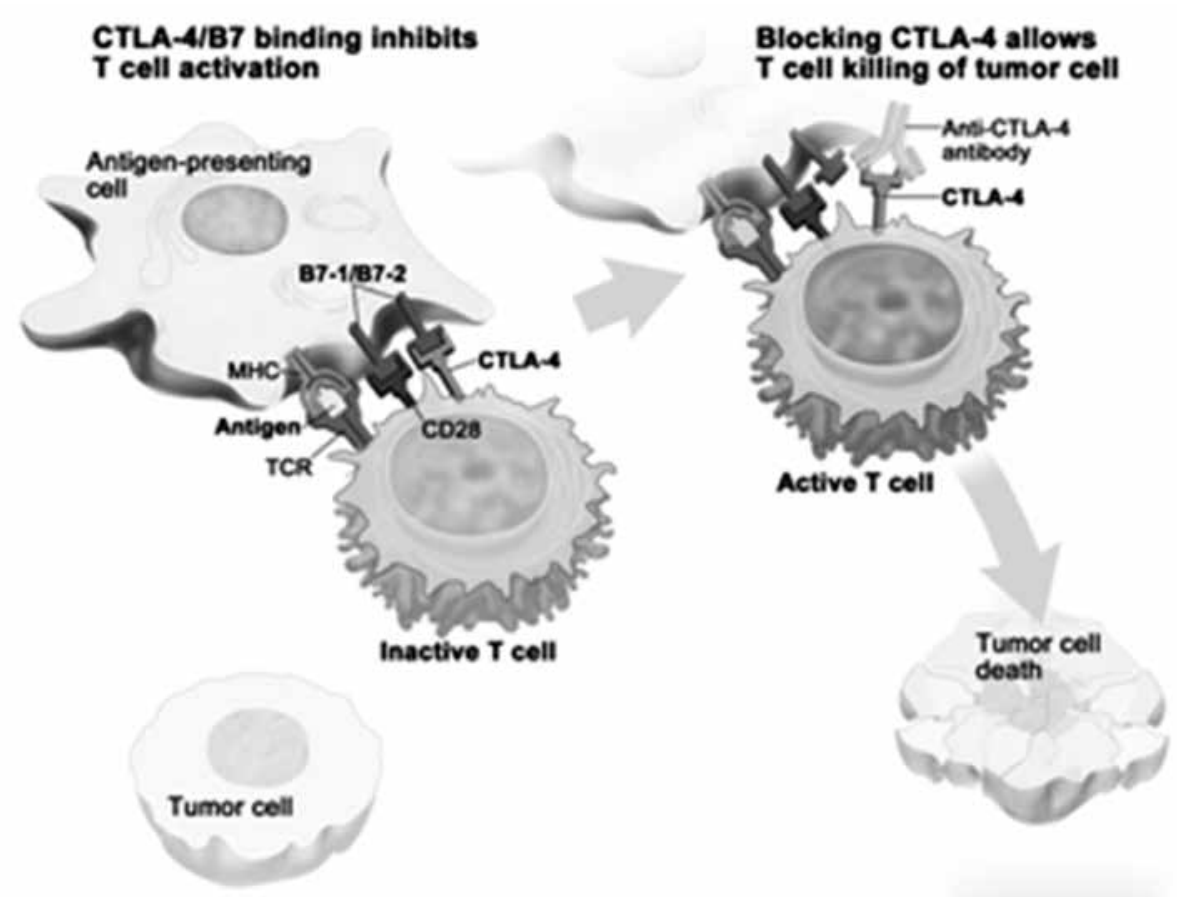

Figure 6. CTLA-4 binds to an antibody, preventing binding to B7, this eliminates the inhibitory effect, thus activating the immune system and removing the brake mechanism on the immune system 
(a)

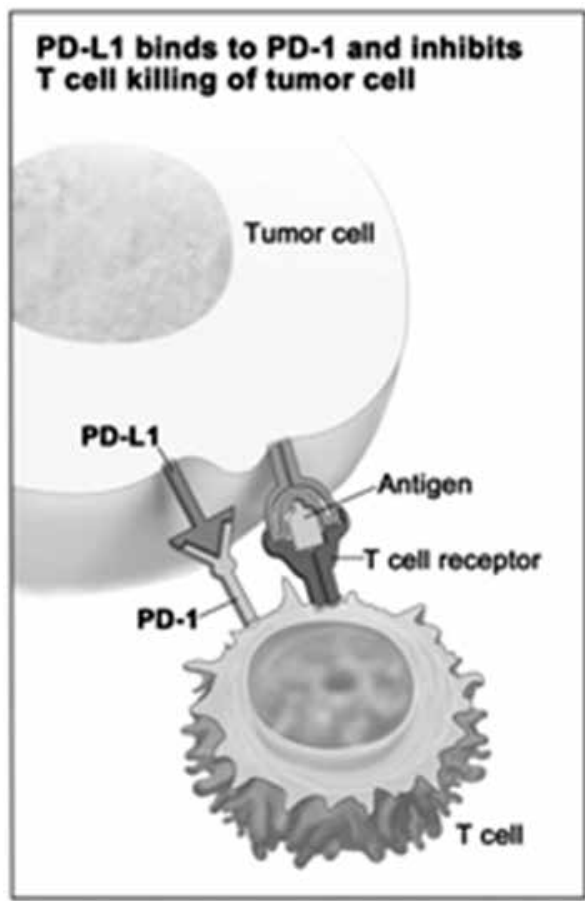

(b)

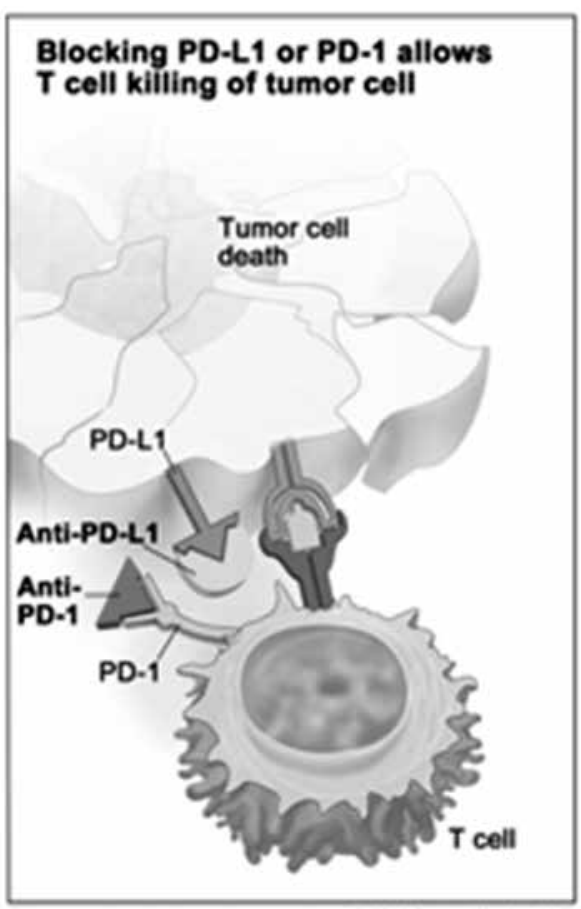

Figure 7. Immune checkpoint inhibitor. Checkpoints such as PD-L1 in tumor cells and PD-1 in T cells help keep immune responses under control. Binding of PD-L1 to PD-1 prevents $\mathrm{T}$ cells from killing tumor cells in the body (left panel). Blocking the binding of PD-L1 to PD-1 with an immune checkpoint inhibitor (anti-PD-L1 or anti-PD-1) allows T cells to kill tumor cells (right panel).

Nivolumab is a PD-1 inhibitor which plays a critical role in the immune response against cancer and is significantly beneficial to melanoma patients. There is evidence of its value in increasing survival time in late stage melanoma patients with poor prognosis. In addition, it has consistently been shown as a well-tolerated drug in generally early clinical studies and multiple Phase III studies. ${ }^{[32]}$

Developments in understanding the biology of immune regulatory pathways of tumors has rapidly increased treatment options for metastatic melanoma. Nivolumab has a relatively better antitumoral response compared to other current immunotherapy options and is a successful drug due to its low rate of adverse reactions. Nivolumab has been shown to have higher success rate compared to other metastatic melanoma therapies. ${ }^{[31]}$

\section{Pembrolizumab}

Pembrolizumab is a completely humanized anti-PD-1 monoclonal antibody that selectively binds to PD-1 receptors on T cells and prevents PD-L1 binding of tumor cells. This lowers tumor tolerance and helps eliminate cancer cells. ${ }^{[33]}$

When used in combination with agents that cause CTLA-4 inhibition, antitumoral efficacy of pembrolizumab has been found higher. ${ }^{[34]}$

\section{BRAF and mitogen-activated protein kinase kinase (MEK) inhibition}

Activator BRAF mutations occur in about $50 \%$ of late stage melanomas. The most common mutations and V600E and V600K. ${ }^{[35]}$

Vemurafenib is a selective BRAF inhibitor effective in blocking tumor growth in melanoma patients with V600E and V600K mutations. However, in patients who do not carry mutant allele, it may cause tumor development by activating BRAF. ${ }^{[36]}$

Blockage of the MAP kinase pathway causes death of cancer cells. ${ }^{[29]}$ Mitogen-activated protein kinase (MAPK) pathway blockage is a class of treatment agents that is used to effectively 
treat late stage melanoma; it mainly consists of BRAF and MEK inhibitors. One study indicated that combination treatment with BRAF and MEK inhibitors was superior to every other treatment modality other than PD-1/L1 blockage and CTLA-4 blockage combination. ${ }^{[37]}$ Studies have shown these agents increased survival of late stage melanoma from nine months to 3.5 years. ${ }^{[29]}$

Trametinib is the first MEK inhibitor to be approved in treating patients with BRAF mutation previously untreated with BRAF inhibitors. It can be used orally and is adenosine triphosphate (ATP) non-competitive selective inhibitor of MEK1 and MEK2.[38]

Most patients have concurrent mutations of BRAF and RAS mutations; RAS mutations can cause resistance to BRAF inhibitors. ${ }^{[39]}$ For these reasons, selective MEK inhibitors are a treatment alternative in melanoma patients with BRAF and RAS mutations. Mitogen-activated protein kinase kinase inhibitors have been shown to reduce tumor burden in patients who carry these mutations. Adverse effects of BRAF inhibitors due to paradoxical MAPK pathway activity have not been observed in the MAP kinase inhibitor trametinib because this pathway is not activated, although trametinib success rate is relatively lower compared to BRAF inhibitors. ${ }^{[40]}$

Cobimetinib is an especially specific inhibitory agent of MEK1/2 in patients with BRAF V600E mutations. Combined use of cobimetinib with vemurafenib has been approved by the FDA. ${ }^{[41]}$ Dabrafenib is another BRAF inhibitor used in melanoma treatment. ${ }^{[40]}$

\section{Other treatment methods}

Talimogene laherparepvec (T-VEC) selectively multiplies in tumor cells and leads to lysis in these cells, allowing the tumor to be recognized by the immune system. T-VEC is an attenuated HSV-1 virus with reduced virulence genes that encodes human granulocyte macrophage colony-stimulating factor (GM-CSF) for acquired immunogenicity. ${ }^{[42]}$ The interferon treatment and IL-2 analogue, aldesleukin, is also used in melanoma treatment. Aldeseuklin stimulates IL-2 as well as increases cytotoxic abilities of $\mathrm{T}$ lymphocytes and NK cells towards cancer cells. ${ }^{[27]}$

\section{Declaration of conflicting interests}

The authors declared no conflicts of interest with respect to the authorship and/or publication of this article.

\section{Funding}

The authors received no financial support for the research and/or authorship of this article.

\section{REFERENCES}

1. Parlak A, Çayırlı M, Parlak N, Ekinci Ş. Melanoma genel bakış. Konuralp Tip Dergisi 2014;6:22-7.

2. Özçelik S, Akyol M. Melanoma Epidemiyolojisi. Türkderm 2007;41:1-5.

3. Doğan Turaçlı İ. Malign melanom oluşum ve ilerleme sürecinde. Gözlenen bazı moleküler değişimler. Turk J Dermatol 2017;11:184-8.

4. Duman N. Kutanöz malign melanom. Acta Oncologica Turcica 2014;47:52-9.

5. Baykal C, Polat Ekinci A. Malign melanoma: Risk factors and major clinical findings. Turk J Dermatol 2015;1:1-7.

6. Mihajlovic M, Vlajkovic S, Jovanovic P, Stefanovic V. Primary mucosal melanomas: a comprehensive review. Int J Clin Exp Pathol 2012;5:739-53.

7. Ünal TD. Histopathological Analysis of cutaneous and mucosal malignant melanoma cases. Bozok Med J 2018;81:31-7.

8. Aktaş H, Ekinci AŞ, Eşbah O. An Acral lentiginous melanoma case with typical dermoscopy findings. An Acral lentiginous melanoma case with typical dermoscopy findings. Acta Oncol Tur 2016;49:61-3.

9. Özbek S, Filiz G. Malign melanomda tedavi prensiplerimiz ve sonuçlarımız. Uludağ Üniversitesi Tip Fakültesi Dergisi 2002;28:13-6.

10. McCourt C, Dolan O, Gormley G. Malignant melanoma: a pictorial review. Ulster Med J 2014;83:103-10.

11. Yılmaz DB, Yılmaz GK, Ünal B, Özkan Ö, Başsorgun Cİ. Desmoplastik malign melanom: Üç olgu sunumu. Güncel Patoloji Dergisi 2017;1(Suppl 1):PS608.

12. Piris A, Mihm MC Jr, Duncan LM. AJCC melanoma staging update: impact on dermatopathology practice and patient management. $\mathrm{J}$ Cutan Pathol 2011;38:394-400.

13. Dickson PV, Gershenwald JE. Staging and prognosis of cutaneous melanoma. Surg Oncol Clin N Am 2011;20:1-17.

14. Rotaru M, Jitian CR, Iancu GM. A 10-year retrospective study of melanoma stage at diagnosis in the academic emergency hospital of Sibiu county. Oncol Lett 2019;17:4145-8.

15. PDQ Adult Treatment Editorial Board. Melanoma Treatment $(\mathrm{PDQ} \otimes)$ : Patient Version. 2019 May 21. In: PDQ Cancer Information Summaries [Internet]. Bethesda (MD): National Cancer Institute (US); 2002. Available at: https://www.ncbi.nlm.nih.gov/books/ NBK65950/ 
16. Rager EL, Bridgeford EP, Ollila DW. Cutaneous melanoma: update on prevention, screening, diagnosis, and treatment. Am Fam Physician 2005;72:269-76.

17. Balch CM, Gershenwald JE, Soong SJ, Thompson JF, Atkins MB, Byrd DR, et al. Final version of 2009 AJCC melanoma staging and classification. J Clin Oncol 2009;27:6199-206.

18. Ward WH, Farma JM, editors. Cutaneous Melanoma: Etiology and Therapy [Internet]. Brisbane (AU): Codon Publications; 2017 Dec. Available at: https://www. ncbi.nlm.nih.gov/pubmed/29461771

19. Glazer AM, Rigel DS, Winkelmann RR, Farberg AS. Clinical Diagnosis of Skin Cancer: Enhancing Inspection and Early Recognition. Dermatol Clin 2017;35:409-16.

20. Ott PA, Berman RS. Surgical approach to primary cutaneous melanoma. Surg Oncol Clin N Am 2011;20:39-56.

21. Thompson JF, Scolyer RA, Uren RF. Surgical management of primary cutaneous melanoma: excision margins and the role of sentinel lymph node examination. Surg Oncol Clin N Am 2006;15:301-18.

22. Wong SL, Balch CM, Hurley P, Agarwala SS, Akhurst TJ, Cochran A, et al. Sentinel lymph node biopsy for melanoma: American Society of Clinical Oncology and Society of Surgical Oncology joint clinical practice guideline. J Clin Oncol 2012;30:2912-8.

23. Sosman JA, Moon J, Tuthill RJ, Warneke JA, Vetto JT, Redman BG, et al. A phase 2 trial of complete resection for stage IV melanoma: results of Southwest Oncology Group Clinical Trial S9430. Cancer 2011;117:4740-6.

24. Bentzen SM, Overgaard J, Thames HD, Overgaard M, Vejby Hansen P, von der Maase $\mathrm{H}$, et al. Clinical radiobiology of malignant melanoma. Radiother Oncol 1989;16:169-82.

25. Burmeister BH, Henderson MA, Ainslie J, Fisher R, Di Iulio J, Smithers BM, et al. Adjuvant radiotherapy versus observation alone for patients at risk of lymphnode field relapse after therapeutic lymphadenectomy for melanoma: a randomised trial. Lancet Oncol 2012;13:589-97.

26. Henderson MA, Burmeister BH, Ainslie J, Fisher R, Di Iulio J, Smithers BM, et al. Adjuvant lymphnode field radiotherapy versus observation only in patients with melanoma at high risk of further lymph-node field relapse after lymphadenectomy (ANZMTG 01.02/TROG 02.01): 6-year follow-up of a phase 3, randomised controlled trial. Lancet Oncol 2015;16:1049-60.

27. Kato J, Hida T, Someya M, Sato S, Sawada M, Horimoto $\mathrm{K}$, et al. Efficacy of combined radiotherapy and anti-programmed death 1 therapy in acral and mucosal melanoma. J Dermatol 2019;46:328-33.

28. Sahni S, Valecha G, Sahni A. Role of Anti-PD-1 Antibodies in Advanced Melanoma: The Era of
Immunotherapy. Cureus 2018;10:3700.

29. Khair DO, Bax HJ, Mele S, Crescioli S, Pellizzari G, Khiabany $\mathrm{A}$, et al. Combining Immune Checkpoint Inhibitors: Established and Emerging Targets and Strategies to Improve Outcomes in Melanoma. Front Immunol 2019;10:453.

30. Hodi FS, O'Day SJ. Improved survival with ipilimumab in patients with metastatic melanoma. N Engl J Med 2010;363:711-23.

31. Koppolu V, Rekha Vasigala VK. Checkpoint immunotherapy by nivolumab for treatment of metastatic melanoma. J Cancer Res Ther 2018;14:1167-75.

32. Gomes F, Serra-Bellver P, Lorigan P. The role of nivolumab in melanoma. Future Oncol 2018;14:124152.

33. Long GV, Atkinson V, Cebon JS, Jameson MB, Fitzharris BM, McNeil CM, et al. Standard-dose pembrolizumab in combination with reduced-dose ipilimumab for patients with advanced melanoma (KEYNOTE-029): an open-label, phase $1 \mathrm{~b}$ trial. Lancet Oncol 2017;18:1202-10.

34. Baksh K, Weber J. Immune checkpoint protein inhibition for cancer: preclinical justification for CTLA-4 and PD-1 blockade and new combinations. Semin Oncol 2015;42:363-77.

35. Andtbacka RH, Kaufman HL, Collichio F, Amatruda T, Senzer N, Chesney J, et al. Talimogene Laherparepvec Improves Durable Response Rate in Patients With Advanced Melanoma. J Clin Oncol 2015;33:2780-8.

36. Tang T, Eldabaje R, Yang L. Current status of biological therapies for the treatment of metastatic melanoma. Anticancer Res 2016;36:3229-41.

37. Qing An, Zhihao Liu. Comparative efficacy and safety of combination therapies for advanced melanoma: a network meta-analysis. BMC Cancer 2019;19:43.

38. Flaherty KT, Robert C, Hersey P, Nathan P, Garbe $C$, Milhem $M$, et al. Improved survival with MEK inhibition in BRAF-mutated melanoma. N Engl J Med 2012;367:107-14.

39. Chapman PB. Mechanisms of resistance to RAF inhibition in melanomas harboring a BRAF mutation. Am Soc Clin Oncol Educ Book 2013.

40. Güngör HK, Akay BN. İlerlemiş melanomada kullanilan güncel tedavi yöntemleri. Turk J Dermatol 2016;10:137-44.

41. Ascierto PA, McArthur GA, Dréno B, Atkinson V, Liszkay G, Di Giacomo AM, et al. Cobimetinib combined with vemurafenib in advanced BRAF(V600)mutant melanoma (coBRIM): updated efficacy results from a randomised, double-blind, phase 3 trial. Lancet Oncol 2016;17:1248-60.

42. Fukuhara $H$, Ino Y, Todo T. Oncolytic virus therapy: A new era of cancer treatment at dawn. Cancer Sci 2016;107:1373-9. 